\title{
Correction to: Discovery and description of a novel sexual weapon in the world's most widely-studied freshwater turtle
}

\author{
Deborah M. Hawkshaw ${ }^{1}$. Patrick D. Moldowan ${ }^{1,2}$. Jacqueline D. Litzgus ${ }^{3}$. \\ Ronald J. Brooks ${ }^{4}$. Njal Rollinson ${ }^{1,2}$
}

Published online: 11 December 2019

(c) Springer Nature Switzerland AG 2019

\section{Correction to: Evolutionary Ecology (2019) 33:889-900 https://doi.org/10.1007/s10682-019-10014-3}

In the original publication of the article, Fig. 2 and Fig. 3 were published with an error. The corrected version of Fig. $\mathbf{2}$ and the caption of Fig. $\mathbf{3}$ is provided in this correction.

Fig. 2 Panels $\mathbf{a}$ and $\mathbf{b}$ are not labelled in Fig. 2. To provide clarification, moving clockwise from the upper left: Panel a (upper left) features an anterio-ventral photograph of a male midland painted turtle demonstrating prominent tomiodonts and serrated anterior carapace. Panel $\mathbf{b}$ (right) is a portrait photograph showing a dorsal perspective on the head and wounded nape of a female midland painted turtle. Panel c (labelled, an inset of panel b) features a close-up of the nape wounds.

Fig. 3 There are two errors in the caption of Fig. 3.

An error was made in referring to the colour representing each sex in Fig. 3, panels a and $\mathbf{b}$. Females are represented in red (not blue) in panel $\mathbf{a}$ and males are represented in

The original article can be found online at https://doi.org/10.1007/s10682-019-10014-3.

Patrick D. Moldowan

patrick.moldowan@mail.utoronto.ca

Deborah M. Hawkshaw

deborah.hawkshaw@mail.utoronto.ca

Jacqueline D. Litzgus

jlitzgus@laurentian.ca

Ronald J. Brooks

rjbrooks@uoguelph.ca

Njal Rollinson

njal.rollinson@mail.utoronto.ca

1 Department of Ecology and Evolutionary Biology, University of Toronto, Toronto, ON M5S 3B2, Canada

2 School of the Environment, University of Toronto, Toronto, ON M5S 3E8, Canada

3 Department of Biology, Laurentian University, 935 Ramsey Lake Road, Sudbury, ON P3E 2C6, Canada

4 Department of Integrative Biology, University of Guelph, Guelph, ON N1G 2W1, Canada 

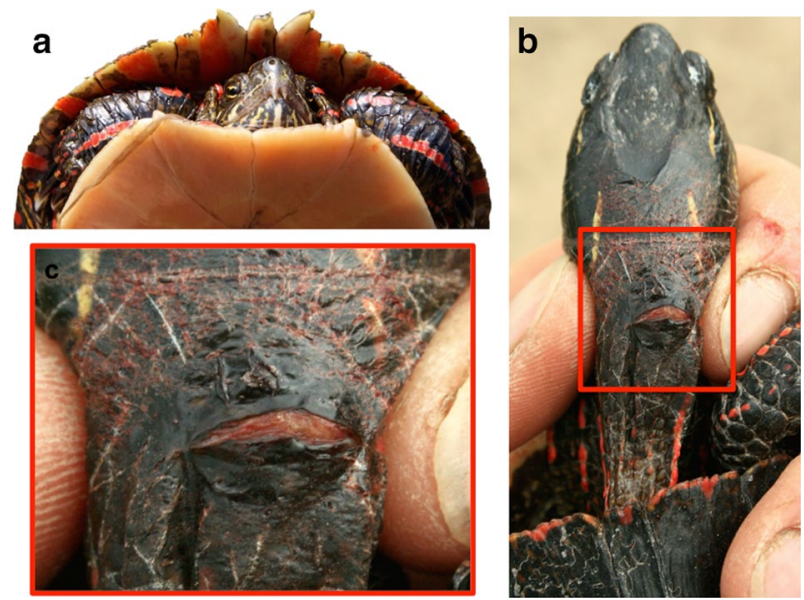

Fig. 2 Anterior carapace as a sexual weapon in the painted turtle, Chrysemys spp. a Male midland painted turtle (C. p. marginata) demonstrating strongly projecting and jagged cervical scute and flanking marginal scutes, as well as prominent bicuspid tomiodonts (Ontario, Canada). b Female midland painted turtle with deep wound on dorsal neck caused by bludgeoning (shell clattering) from the anterior carapace of a male. c Inset of neck wound. Note the two parallel short gash wounds anterior to the large open wound. The parallel gashes are caused by the sexually size dimorphic, bicuspid tomiodonts of males during sexual coercion (Figs. 1a, 2a; Moldowan et al. 2016a, b). See video S1 for example of how coercive behaviour leads to wounding. Photo (a) courtesy Cortney LeGros, and photos (b)/(c) by Patrick D. Moldowan

blue (not red) in panel b. The opening lines of the corrected caption should read: "Mean shape configuration of the anterior carapace, and relationships between anterior carapace shape and body size for male and female painted turtle (Chrysemys spp.). Averaged anterior carapace shape of a female (in red) and b male (in blue) painted turtles".

Regarding Fig. 3 panels $\mathbf{d - g}$, the regression plots show predicted anterior carapace shape scores plotted against body size, presented as midline plastron length (not log midline plastron length, as stated). The corrected caption pertaining to panels $\mathbf{d}-\mathbf{g}$ should read: "Regression plots of predicted anterior carapace shape scores and body size (midline plastron length) of males (blue) and females (red)".

Publisher's Note Springer Nature remains neutral with regard to jurisdictional claims in published maps and institutional affiliations. 